\title{
Favorable Trends of Lung Cancer Mortality-to-Incidence Ratios in Countries With High Computed Tomography Density
}

\author{
Yao-Tung Wang \\ Chung Shan Medical University Hospital \\ Han-Ru Wu \\ Chung Shan Medical University \\ Ya-Chuan Chang \\ Chung Shan Medical University \\ Chia-Ying Yu \\ Chung Shan Medical University \\ Yao-Chen Wang \\ Chung Shan Medical University Hospital \\ Wen-Wei Sung ( $\nabla$ flutewayne@gmail.con ) \\ Chung Shan Medical University Hospital
}

\section{Research}

Keywords: lung cancer, mortality, incidence, mortality-to-incidence ratio, expenditure, computed tomography

Posted Date: May 13th, 2021

DOl: https://doi.org/10.21203/rs.3.rs-480649/v1

License: (1) (1) This work is licensed under a Creative Commons Attribution 4.0 International License. Read Full License 


\section{Abstract}

Background: Prognoses for lung cancer deteriorate dramatically with the progression of cancer stages. Therefore, early screening by techniques such as lowdose computed tomography (LDCT) is critical. However, the epidemiology regarding the association between the popularization of CT and the prognosis for lung cancer is not known.

Methods: Data were obtained from GLOBOCAN and the health data and statistics of World Health Organization. MIRs and the changes in MIR over time ( $\delta$ MIR), which were calculated as the difference between MIRs in 2018 and 2012, were used to evaluate the correlation to CT density disparities via Spearman's rank correlation coefficient.

Results: Countries with zero CT density presented a relatively low incidence crude rate and a relatively high MIR in 2018 and a negative $\delta$ MIR. Conversely, countries with CT density over 30 had a positive $\delta$ MIR. The CT density was significantly associated with human development index (HDI) score and MIR in 2018 but demonstrated no association with MIR in 2012. The linear correlation between CT density and $\delta$ MIR also shows a significant association.

Conclusion: CT density was significantly associated with MIR in 2018 and with $\delta$ MIR, indicating favorable clinical outcomes in countries with popularization of CT.

\section{Introduction}

Lung cancer used to be a rare disease; however, since the start of the 21 st century, it has become the cancer with the highest incidence and mortality worldwide. In 2018, the number of new cases of lung cancer was as high as 2,093,876 and deaths due to lung cancer totaled 1,761,007 [1]. These data are strikingly high and have aroused public concern. Moreover, mortality rates in 2018 closely paralleled the incidence rate in lung cancer worldwide, meaning a poor treatment outcome for lung cancer after diagnosis [1]. Lung cancer is usually diagnosed in advanced stages [2], and the prognosis at this period is extremely poor. Therefore, early diagnosis is a true public concern.

If lung cancer can be diagnosed early, the five-year survival rate can rise to $60-80 \%$, much higher than in stage 3 (16\%) and stage 4 (less than $10 \%$ ) [3]. Unfortunately, early diagnosis becomes quite difficult because lung cancer in its early stage is asymptomatic and its detection depends on image surveys, such as X-ray or CT. However, compared to CT screening, the use of X-rays to find abnormalities in lung cancer, and especially small lesions, if far more difficult. In $90 \%$ of early lung cancer cases, a misdiagnosis occurs when X-rays are used [4], due to the difficulty in distinguishing lung lesions from bones, pulmonary vessels, mediastinal structures, and other complex anatomical structures [4]. Conversely, CT has high sensitivity and can distinguish $83 \%$ to $91 \%$ of these lesions [5].

Low-dose computed tomography (LDCT), as the name suggests, allows screening at a lower radiation dose (1.0-1.4mSV) compared to traditional CT [6]. Moreover, related research showed no significant differences between LDCT and CT when used for lung cancer screening, as the concordance rate for the diagnoses was approximately 80\% [7]. CT mainly detects lung nodules and establishes baseline screening for lung cancer [8]. However, the CT density, defined as the total density of CT facilities per million population, varies dramatically from region to region. CT facilities require abundant funds, so their construction might be influenced by the economic development of a given country. Based on the important role of LDCT in lung cancer prognosis and the regional differences in CT density, we considered that CT density might affect the worldwide mortality-to-incidence ratios (MIRs). Many previous studies have focused on the effectiveness of LDCT by analyzing the correlation between regular LDCT screening and lung cancer mortality rates, whereas few studies have explored the real situation regarding the availability of LDCT worldwide. Here, we have provided a comprehensive view of the relevance of CT availability to lung cancer prognosis according to regions by analyzing the association between CT density and MIRs.

\section{Materials And Methods}

Lung cancer (ICD-10 C33-34) epidemiological data were obtained from the GLOBOCAN database (https://gco.iarc.fr/today/) estimates from 2012 and 2018 for 185 countries. The human development index (HDI) was obtained from the United Nations Development Programme, Human Development Report Office (http://hdr.undp.org/en). Data for CT density for 2013 were obtained from the Global Health Observatory data repository (https://www.who.int/data/gho). The data on health expenditures, including per capita current health expenditure (CHE) and current health expenditure on gross domestic product (CHE/GDP) (ratio of $\mathrm{CHE}$ to the \% of GDP), were obtained from the World Health Statistics database (https://www.who.int/gho/publications/world_health_statistics/en/). MIR was defined as the ratio of the crude rate of mortality to the crude rate of incidence, as previously described [9-12]. The MIR over time ( $\delta$ MIR) was defined as the difference between the MIRs of 2012 and 2018 $(\delta \mathrm{MIR}=\mathrm{MIR}$ [in 2012] - MIR [in 2018]) [13].

The exclusion criteria for country selection included data missing for the CT density $(\mathrm{N}=60)$, missing data for $\mathrm{MIR} / \mathrm{HDI} / \mathrm{CHE}(\mathrm{N}=3)$, and outliers for the CT density $(\mathrm{N}=2)$. A total of 115 countries were included in the final analysis.

The associations between the MIR, $\delta \mathrm{MIR}$, and other factors among the various countries were estimated using a Spearman's rank correlation coefficient calculated using SPSS statistical software version 15.0 (SPSS, Inc., Chicago, IL). Values of $p<0.05$ were considered statistically significant. Scatterplots were generated using SigmaPlot.

\section{Result}

Human development index and the CT density in selected countries 
Table 1 demonstrates the scores and ranks for the human development index and the CT density according to countries. Countries with a CT density less than 0.01 are the African Republic, Guinea-Bissau, Guinea, and Vanuatu. As expected, these countries also rank low in terms of HDI (187, 174, 176, and 122, respectively). By contrast, countries with CT density higher than 20 all rank in the top 50, except for Lebanon. The highest CT density is in Iceland (39.45), and the lowest CT density are in Guinea-Bissau and Guinea $(0.00)$.

CT density and incidence crude rates, MIR, and MIR disparity of lung cancer

Those countries with zero CT density, namely the African Republic, Guinea-Bissau, Guinea, and Vanuatu, also have a incidence crude rate lower than 10 (2.2, 2.8, 2.4 and 8.0, respectively). Furthermore, their MIR in 2018 was higher than 0.9 and the $\delta$ MIR values were all negative. In terms of $\delta$ MIR, countries with a CT density over 30 , such as Iceland, Greece, and South Korea, have a positive $\delta$ MIR $(0.15,0.12$, and 0.11 , respectively). Conversely, Vanuatu had an extremely low $\delta$ MIR (-0.14) and the highest MIR in 2018 (1.06) and had a CT density of zero.

CT density is significantly associated with HDI score.

Figure 1 presents the association between CT density and HDI score according to all selected countries, grouped according to $\mathrm{HDI}$ score $(<0.70$ and $>0.70$, respectively). All three groups show a significant association between CT density and HDI $(\rho=0.867, p<0.001$, Figure $1 A ; \rho=0.651$, $p<0.001$, Figure $1 B$; $\rho=0.508, p<0.001$, Figure $1 C$, respectively).

The association between CT density, MIR in 2012 and 2018, and $\delta$ MIR.

The CT density is significantly associated with MIR in 2018 in figure $2(\rho=-0.581, p<0.001$, Figure $2 B$ ) However, no association was noted between CT density and MIR in $2012(\rho=-0.104, p=0.268$, Figure 2A). However, analysis of the linear correlation between CT density and $\delta$ MIR revealed a significant association $(\rho=0.455, p<0.001$, Figure $2 C)$.

\section{Discussion}

The previous large National Lung Screening Trial (NLST) with an enrolment of 53,454 persons, focused on the effect of routine LDCT screening on mortality reduction, but only concluded that ever-smokers were at high risk [14, 15]. Our study, also based on the NLST, generally explored the association between CT density distribution and the prognosis of lung cancer and revealed the concordance between the geographical distribution of actual CT density and prognosis of lung cancer. Adequate CT facilities might better meet the needs of people eligible for routine screening, thereby improving the prognosis of lung cancer.

According to the NLST, the LDCT can reduce lung cancer mortality by $20 \%$ compared to X-rays, and follow-up European studies also support the effectiveness of LDCT $[16,17]$. LDCT mainly detects nodules in the lung. The size, growth rate, morphology, and location of the nodules are references used for malignant or benign judgments. Related research shows that most lung cancer is confirmed in large nodules, whereas lung nodule counts have yet to be proved to determine malignancy [18]. Compared to the high misdiagnosis rate and the increased cost and time-consuming shortcomings of MIRs, regular LDCT screening might be a more practicable form of radiography for close tracking of new large nodules [4, 19]. Due to the effectiveness of LDCT screening, the United States recommends that current and former smokers aged 55 through 80 years with a 30 -year history of smoking receive routine LDCT screening [20].

The recommendation for LDCT screening of high-risk people was based on NLST research and was announced in 2011 [14, 20 ]. This might explain the lack of a significant association between CT density and MIR in 2012 in our analysis and the subsequent significant association in 2018. Furthermore, CT density is also significantly associated with HDI. According to previous research on the cost-effectiveness of CT, which has an incremental cost-effectiveness ratio (ICER) of $£ 10,069$ per quality-adjusted life year (QALY) [21]. This number might be an imposing burden for low-HDI countries. In other words, the CT density might also reflect the amount of money invested in medical care.

To the best of our knowledge, our study is the first to aim at identifying an association between CT density and the MIRs of lung cancer. However, this study still has some limitations. One is that only countries with a CT density recorded by the WHO were included in our study. Another is that the level of CT density might not be representative of the people that actually receive routine screening. A third limitation is that previous research showed no significant association between LDCT and the decrease in lung cancer mortality rates in males, meaning that the study might ignore sexual differences [5]. Despite these limitations, our study still demonstrates that the prognosis of lung cancer might improve as the CT density rises.

\section{Abbreviations}

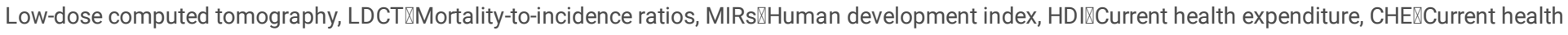

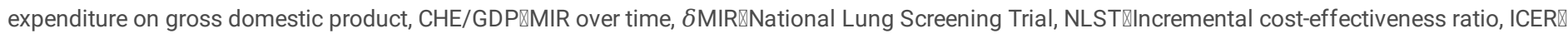
Quality-adjusted life year, QALY

\section{Declarations}

\section{Ethics approval and consent to participate}

Not applicable. 
Not applicable.

\section{Availability of data and materials}

The datasets [Cancer epidemiological data] for this study can be found in the [GLOBOCAN project] [http://gco.iarc.fr/]. The datasets [HDI data] for this study can be found in the [Human De-velopment Report Office of the United Nations Development Programme] [http://hdr.undp.org/en]. The datasets [Health expenditures data] for this study can be found in the [World Health Statistics database] [https://www.who.int/gho/publications/world_health_statistics/en/].

\section{Conflicts of Interest}

The authors declare no conflict of interest.

\section{Funding}

This research received no external funding.

\section{Author contributions}

Conceptualization, Yao-Tung Wang, Han-Ru Wu, and Wen-Wei Sung; Data curation, Ya-Chuan Chang, and Chia-Ying Yu; Formal analysis, Ya-Chuan Chang, and Chia-Ying Yu; Methodology, Han-Ru Wu, and Wen-Wei Sung; Supervision, Yao-Chen Wang, and Wen-Wei Sung; Writing - original draft, Han-Ru Wu and Wen-Wei Sung; Writing - review \& editing, Yao-Tung Wang and Yao-Chen Wang.

\section{Acknowledgement}

Not applicable.

\section{References}

1. Bray F, Ferlay J, Soerjomataram I, Siegel RL, Torre LA, Jemal A. Global cancer statistics 2018: GLOBOCAN estimates of incidence and mortality worldwide for 36 cancers in 185 countries. CA Cancer J Clin. 2018; 68: 394-424.

2. Hoffman RM, Sanchez R. Lung Cancer Screening. Med Clin North Am. 2017; 101: 769-85.

3. Goldstraw P. The 7th Edition of TNM for Lung and Pleural Tumours. Journal of Clinical and Analytical Medicine. 2012 ; 3: $123-7$.

4. Del Ciello A, Franchi P, Contegiacomo A, Cicchetti G, Bonomo L, Larici AR. Missed lung cancer: when, where, and why? Diagn Interv Radiol. 2017; 23: 11826.

5. Becker N, Motsch E, Trotter A, Heussel CP, Dienemann H, Schnabel PA, Kauczor HU, Maldonado SG, Miller AB, Kaaks R, Delorme S. Lung cancer mortality reduction by LDCT screening-Results from the randomized German LUSI trial. Int J Cancer. 2019.

6. Rampinelli C, De Marco P, Origgi D, Maisonneuve P, Casiraghi M, Veronesi G, Spaggiari L, Bellomi M. Exposure to low dose computed tomography for lung cancer screening and risk of cancer: secondary analysis of trial data and risk-benefit analysis. 2017; 356 : j347.

7. Ono K, Hiraoka T, Ono A, Komatsu E, Shigenaga T, Takaki H, Maeda T, Ogusu H, Yoshida S, Fukushima K, Kai M. Low-dose CT scan screening for lung cancer: comparison of images and radiation doses between low-dose CT and follow-up standard diagnostic CT. Springerplus. 2013 ; 2: 393.

8. Heuvelmans MA, Vonder M, Rook M, Groen HJM, De Bock GH, Xie X, ljzerman MJ, Vliegenthart R, Oudkerk M. Screening for Early Lung Cancer, Chronic Obstructive Pulmonary Disease, and Cardiovascular Disease (the Big-3) Using Low-dose Chest Computed Tomography: Current Evidence and Technical Considerations. J Thorac Imaging. 2019; 34: 160-9.

9. Sunkara V, Hebert JR. The colorectal cancer mortality-to-incidence ratio as an indicator of global cancer screening and care. Cancer. 2015; 121 : 1563-9.

10. Chen SL, Wang SC, Ho CJ, Kao YL, Hsieh TY, Chen WJ, Chen CJ, Wu PR, Ko JL, Lee H, Sung WW. Prostate Cancer Mortality-To-Incidence Ratios Are Associated with Cancer Care Disparities in 35 Countries. Sci Rep. 2017; 7: 40003.

11. Sung WW, Wang SC, Hsieh TY, Ho CJ, Huang CY, Kao YL, Chen WJ, Chen SL. Favorable mortality-to-incidence ratios of kidney Cancer are associated with advanced health care systems. BMC Cancer. 2018; 18: 792.

12. Wang SC, Sung WW, Kao YL, Hsieh TY, Chen WJ, Chen SL, Chang HR. The gender difference and mortality-to-incidence ratio relate to health care disparities in bladder cancer: National estimates from 33 countries. Sci Rep. 2017; 7: 4360.

13. Wang SC, Chan L, Hsieh TY, Wang CH, Chen SL, Sung WW. Limited improvement in prostate cancer mortality-to-incidence ratios in countries with high health care expenditures. Aging (Albany NY). 2020; 12: 21308-15.

14. Reduced Lung-Cancer Mortality with Low-Dose Computed Tomographic Screening. 2011; 365: 395-409.

15. Pinsky PF. Lung cancer screening with low-dose CT: a world-wide view. Transl Lung Cancer Res. 2018; 7: 234-42.

16. Odahowski CL, Zahnd WE, Eberth JM. Challenges and Opportunities for Lung Cancer Screening in Rural America. J Am Coll Radiol. 2019; 16: 590-5.

17. Yousaf-Khan U, van der Aalst C, de Jong PA, Heuvelmans M, Scholten E, Lammers JW, van Ooijen P, Nackaerts K, Weenink C, Groen H, Vliegenthart R, Ten Haaf K, Oudkerk M, et al. Final screening round of the NELSON lung cancer screening trial: the effect of a 2.5-year screening interval. Thorax. 2017; 72: 48-56. 
18. Heuvelmans MA, Walter JE, Peters RB, Bock GH, Yousaf-Khan U, Aalst CMV, Groen HJM, Nackaerts K, Ooijen PMV, Koning HJ, Oudkerk M, Vliegenthart R. Relationship between nodule count and lung cancer probability in baseline CT lung cancer screening: The NELSON study. Lung Cancer. 2017; 113: 4550.

19. Biederer J, Ohno Y, Hatabu H, Schiebler ML, van Beek EJR, Vogel-Claussen J, Kauczor HU. Screening for lung cancer: Does MRI have a role? Eur J Radiol. 2017; 86: 353-60.

20. Moyer VA. Screening for lung cancer: U.S. Preventive Services Task Force recommendation statement. Ann Intern Med. 2014; 160: 330-8.

21. Lopci E, Castello A, Morenghi E, Tanzi D, Cavuto S, Lutman F, Chiesa G, Vanni E, Alloisio M, Infante M. Cost-effectiveness of second-line diagnostic investigations in patients included in the DANTE trial: a randomized controlled trial of lung cancer screening with low-dose computed tomography. Nucl Med Commun. 2019; 40: 508-16.

\section{Tables}

Table 1. Summary of human development index, CT density, cancer incidence, cancer mortality, and mortality-to-incidence ratio in lung cancer of selected countries. 


\begin{tabular}{|c|c|c|c|c|c|c|c|c|c|c|c|c|}
\hline \multirow[b]{2}{*}{ Country } & \multicolumn{3}{|c|}{$\begin{array}{l}\text { Human } \\
\text { Development } \\
\text { Index }\end{array}$} & \multicolumn{3}{|c|}{ Incidence } & \multicolumn{3}{|l|}{ Mortality } & \multicolumn{3}{|c|}{$\begin{array}{l}\text { Mortality-to-incidence } \\
\text { Ratio }\end{array}$} \\
\hline & Score & Rank & $\begin{array}{l}\text { CT } \\
\text { density }\end{array}$ & Number & ASR & $\mathrm{CR}$ & Number & ASR & $\mathrm{CR}$ & 2012 & 2018 & $\delta \mathrm{MIR}$ \\
\hline Afghanistan & 0.479 & 153 & 0.20 & 1019 & 2.8 & 6.1 & 1022 & 2.8 & 6.1 & 0.87 & 1.00 & -0.13 \\
\hline Albania & 0.771 & 61 & 5.36 & 1087 & 37.4 & 21.1 & 961 & 33.1 & 18.1 & 0.95 & 0.89 & 0.06 \\
\hline Angola & 0.537 & 135 & 0.42 & 401 & 1.3 & 3.2 & 396 & 1.3 & 3.2 & 0.88 & 1.00 & -0.12 \\
\hline Armenia & 0.737 & 75 & 3.02 & 1266 & 43.7 & 27.8 & 1186 & 40.9 & 26.1 & 0.90 & 0.94 & -0.04 \\
\hline Austria & 0.899 & 15 & 28.49 & 4845 & 56.9 & 27.3 & 4012 & 47.1 & 21.1 & 0.80 & 0.83 & -0.03 \\
\hline Azerbaijan & 0.736 & 78 & 1.06 & 1346 & 13.6 & 12.5 & 1265 & 12.8 & 11.7 & 0.88 & 0.94 & -0.06 \\
\hline Bahamas & 0.797 & 51 & 13.25 & 33 & 8.3 & 6.1 & 32 & 8.1 & 6.0 & 0.93 & 0.98 & -0.05 \\
\hline Barbados & 0.811 & 44 & 7.03 & 46 & 16.3 & 8.7 & 41 & 14.5 & 7.6 & 1.00 & 0.89 & 0.11 \\
\hline Belarus & 0.803 & 46 & 6.20 & 4118 & 44.3 & 25.0 & 2839 & 30.5 & 17.0 & 0.85 & 0.69 & 0.16 \\
\hline Belize & 0.706 & 90 & 12.05 & 25 & 6.6 & 9.8 & 25 & 6.6 & 9.8 & 0.96 & 1.00 & -0.04 \\
\hline Benin & 0.489 & 149 & 0.29 & 65 & 0.6 & 1.0 & 64 & 0.6 & 1.0 & 1.00 & 0.98 & 0.02 \\
\hline Bhutan & 0.591 & 120 & 1.33 & 48 & 5.9 & 7.9 & 44 & 5.4 & 7.3 & 0.94 & 0.92 & 0.02 \\
\hline $\begin{array}{l}\text { Bosnia and } \\
\text { Herzegovina }\end{array}$ & 0.741 & 73 & 16.45 & 2379 & 69.1 & 35.9 & 2034 & 59.0 & 29.5 & 1.01 & 0.85 & 0.16 \\
\hline Botswana & 0.687 & 96 & 0.99 & 45 & 1.9 & 2.9 & 44 & 1.9 & 2.9 & 0.91 & 1.00 & -0.09 \\
\hline Burkina Faso & 0.394 & 170 & 0.65 & 243 & 1.2 & 2.7 & 231 & 1.2 & 2.6 & 0.89 & 1.00 & -0.11 \\
\hline Burundi & 0.416 & 166 & 0.20 & 86 & 0.8 & 1.6 & 81 & 0.7 & 1.6 & 0.89 & 0.94 & -0.05 \\
\hline Cambodia & 0.548 & 129 & 1.19 & 1544 & 9.5 & 13.0 & 1497 & 9.2 & 12.6 & 0.88 & 0.97 & -0.09 \\
\hline Cameroon & 0.524 & 138 & 0.63 & 294 & 1.2 & 2.3 & 293 & 1.2 & 2.3 & 0.89 & 1.00 & -0.11 \\
\hline Canada & 0.906 & 12 & 13.76 & 22340 & 61.9 & 28.4 & 17566 & 48.7 & 21.7 & 0.79 & 0.79 & 0.00 \\
\hline $\begin{array}{l}\text { Central African } \\
\text { Republic }\end{array}$ & 0.370 & 172 & 0.00 & 56 & 1.2 & 2.2 & 54 & 1.1 & 2.1 & 0.89 & 0.92 & -0.03 \\
\hline Chad & 0.393 & 171 & 0.08 & 102 & 0.7 & 1.5 & 95 & 0.6 & 1.5 & 0.83 & 0.93 & -0.10 \\
\hline Chile & 0.818 & 43 & 12.60 & 3432 & 19.1 & 12.5 & 3163 & 17.6 & 11.5 & 0.96 & 0.92 & 0.04 \\
\hline Comoros & 0.529 & 137 & 1.36 & 1 & 0.1 & 0.2 & 1 & 0.1 & 0.2 & 1.00 & 1.00 & 0.00 \\
\hline Costa Rica & 0.774 & 59 & 5.13 & 405 & 8.3 & 6.1 & 335 & 6.8 & 4.9 & 0.70 & 0.82 & -0.12 \\
\hline Côte d'Ivoire & 0.467 & 155 & 0.69 & 276 & 1.1 & 2.2 & 267 & 1.1 & 2.2 & 0.90 & 1.00 & -0.10 \\
\hline Croatia & 0.820 & 42 & 14.92 & 2817 & 69.3 & 31.7 & 2684 & 66.0 & 29.7 & 0.91 & 0.95 & -0.04 \\
\hline Cuba & 0.764 & 66 & 4.79 & 6318 & 56.1 & 29.9 & 5267 & 46.8 & 24.5 & 0.94 & 0.83 & 0.11 \\
\hline Cyprus & 0.852 & 30 & 25.41 & 454 & 38.7 & 23.0 & 456 & 38.9 & 22.7 & 0.93 & 1.01 & -0.08 \\
\hline Czechia & 0.865 & 26 & 12.99 & 6204 & 59.6 & 26.5 & 4821 & 46.3 & 20.2 & 0.78 & 0.78 & 0.00 \\
\hline Denmark & 0.924 & 5 & 23.85 & 4546 & 80.8 & 35.2 & 3487 & 62.0 & 25.5 & 0.83 & 0.77 & 0.06 \\
\hline $\begin{array}{l}\text { Dominican } \\
\text { Republic }\end{array}$ & 0.708 & 89 & 13.89 & 1236 & 11.5 & 11.7 & 1106 & 10.2 & 10.3 & 0.90 & 0.89 & 0.01 \\
\hline Ecuador & 0.740 & 74 & 1.59 & 965 & 5.8 & 5.5 & 888 & 5.3 & 5.0 & 1.01 & 0.91 & 0.10 \\
\hline El Salvador & 0.660 & 107 & 4.73 & 362 & 5.7 & 4.9 & 343 & 5.4 & 4.6 & 0.89 & 0.95 & -0.06 \\
\hline Eritrea & 0.422 & 165 & 0.32 & 79 & 1.5 & 2.8 & 77 & 1.5 & 2.8 & 0.91 & 1.00 & -0.09 \\
\hline Estonia & 0.859 & 27 & 15.54 & 790 & 62.1 & 28.8 & 653 & 51.3 & 22.7 & 1.05 & 0.83 & 0.22 \\
\hline Eswatini/Swaziland & 0.542 & 133 & 2.40 & 18 & 1.3 & 2.5 & 18 & 1.3 & 2.6 & 1.00 & 1.00 & 0.00 \\
\hline
\end{tabular}




\begin{tabular}{|c|c|c|c|c|c|c|c|c|c|c|c|c|}
\hline Ethiopia & 0.429 & 163 & 0.36 & 2033 & 1.9 & 3.5 & 2032 & 1.9 & 3.5 & 0.89 & 1.00 & -0.11 \\
\hline Fiji & 0.702 & 91 & 3.40 & 54 & 5.9 & 5.9 & 51 & 5.6 & 5.6 & 0.88 & 0.95 & -0.07 \\
\hline Finland & 0.908 & 9 & 20.09 & 2480 & 46.0 & 18.4 & 2035 & 37.7 & 14.7 & 0.86 & 0.82 & 0.04 \\
\hline Gabon & 0.672 & 103 & 3.59 & 95 & 4.6 & 6.7 & 92 & 4.5 & 6.6 & 0.93 & 0.98 & -0.05 \\
\hline Georgia & 0.749 & 69 & 8.75 & 1148 & 29.8 & 16.7 & 1070 & 27.8 & 15.9 & 0.90 & 0.93 & -0.03 \\
\hline Ghana & 0.570 & 124 & 0.15 & 234 & 0.8 & 1.4 & 217 & 0.7 & 1.3 & 0.86 & 0.93 & -0.06 \\
\hline Greece & 0.856 & 28 & 33.16 & 9229 & 85.6 & 39.6 & 7498 & 69.5 & 30.8 & 0.93 & 0.81 & 0.12 \\
\hline Guinea-Bissau & 0.437 & 161 & 0.00 & 18 & 0.9 & 1.8 & 18 & 0.9 & 1.8 & 1.00 & 1.00 & 0.00 \\
\hline Guinea & 0.431 & 162 & 0.00 & 184 & 1.4 & 2.4 & 165 & 1.3 & 2.2 & 0.88 & 0.93 & -0.05 \\
\hline Guyana & 0.652 & 108 & 3.75 & 21 & 2.7 & 3.0 & 21 & 2.7 & 3.0 & 0.94 & 1.00 & -0.06 \\
\hline Haiti & 0.478 & 154 & 0.29 & 491 & 4.4 & 5.9 & 441 & 4.0 & 5.4 & 0.91 & 0.91 & 0.00 \\
\hline Honduras & 0.600 & 118 & 2.10 & 363 & 3.9 & 5.5 & 321 & 3.4 & 4.8 & 0.93 & 0.87 & 0.06 \\
\hline Hungary & 0.826 & 39 & 6.63 & 10550 & 111.1 & 55.8 & 8457 & 89.0 & 43.5 & 0.87 & 0.80 & 0.07 \\
\hline Iceland & 0.908 & 10 & 39.45 & 174 & 52.5 & 29.6 & 125 & 37.7 & 19.4 & 0.87 & 0.72 & 0.15 \\
\hline Iraq & 0.662 & 106 & 2.22 & 2075 & 5.3 & 10.4 & 2019 & 5.1 & 10.1 & 0.90 & 0.96 & -0.06 \\
\hline Ireland & 0.899 & 16 & 4.54 & 2694 & 56.9 & 31.8 & 1778 & 37.6 & 20.2 & 0.78 & 0.66 & 0.12 \\
\hline Israel & 0.893 & 19 & 7.50 & 2304 & 27.7 & 20.1 & 1997 & 24.0 & 17.1 & 0.86 & 0.87 & -0.01 \\
\hline Jamaica & 0.722 & 84 & 1.44 & 481 & 16.8 & 13.2 & 439 & 15.3 & 11.9 & 0.90 & 0.91 & -0.01 \\
\hline Jordan & 0.726 & 83 & 5.50 & 1093 & 11.1 & 17.3 & 972 & 9.8 & 15.6 & 0.90 & 0.88 & 0.02 \\
\hline Kazakhstan & 0.782 & 57 & 1.46 & 4239 & 23.1 & 21.3 & 3798 & 20.7 & 19.1 & 0.90 & 0.90 & 0.00 \\
\hline Kenya & 0.545 & 132 & 0.25 & 665 & 1.3 & 2.9 & 651 & 1.3 & 2.9 & 0.92 & 1.00 & -0.08 \\
\hline Kyrgyzstan & 0.649 & 109 & 0.90 & 657 & 10.7 & 13.9 & 606 & 9.9 & 12.7 & 0.89 & 0.93 & -0.04 \\
\hline Laos & 0.569 & 125 & 0.74 & 861 & 12.4 & 18.3 & 829 & 11.9 & 17.8 & 0.87 & 0.96 & -0.09 \\
\hline Lebanon & 0.744 & 70 & 25.09 & 1546 & 25.5 & 22.2 & 1396 & 23.1 & 19.9 & 0.89 & 0.91 & -0.02 \\
\hline Lithuania & 0.835 & 36 & 20.22 & 1530 & 54.6 & 26.0 & 1269 & 45.3 & 21.1 & 0.83 & 0.83 & 0.00 \\
\hline Luxembourg & 0.892 & 20 & 18.85 & 278 & 48.1 & 27.0 & 203 & 35.1 & 19.1 & 0.84 & 0.73 & 0.11 \\
\hline Madagascar & 0.507 & 141 & 0.13 & 148 & 0.6 & 1.0 & 133 & 0.5 & 0.9 & 0.89 & 0.91 & -0.02 \\
\hline Malawi & 0.452 & 158 & 0.31 & 127 & 0.7 & 1.5 & 121 & 0.6 & 1.4 & 0.80 & 0.95 & -0.15 \\
\hline Malaysia & 0.782 & 56 & 6.43 & 4547 & 14.2 & 14.7 & 3903 & 12.2 & 12.6 & 0.94 & 0.86 & 0.08 \\
\hline Maldives & 0.688 & 95 & 5.80 & 38 & 8.6 & 11.9 & 32 & 7.2 & 10.3 & 1.00 & 0.84 & 0.16 \\
\hline Mali & 0.408 & 168 & 0.20 & 246 & 1.3 & 3.0 & 239 & 1.3 & 3.0 & 0.91 & 1.00 & -0.09 \\
\hline Malta & 0.854 & 29 & 9.32 & 184 & 43.3 & 18.3 & 170 & 40.0 & 16.4 & 0.77 & 0.92 & -0.15 \\
\hline Mauritania & 0.503 & 143 & 1.54 & 60 & 1.3 & 2.4 & 60 & 1.3 & 2.4 & 1.00 & 1.00 & 0.00 \\
\hline Mauritius & 0.768 & 63 & 6.43 & 196 & 15.6 & 9.9 & 172 & 13.7 & 8.6 & 1.37 & 0.88 & 0.49 \\
\hline Mexico & 0.752 & 68 & 3.65 & 6952 & 5.4 & 5.4 & 5921 & 4.6 & 4.6 & 0.90 & 0.85 & 0.05 \\
\hline Moldova & 0.693 & 94 & 5.45 & 1678 & 41.9 & 27.3 & 1302 & 32.5 & 21.0 & 0.83 & 0.78 & 0.05 \\
\hline Mongolia & 0.719 & 87 & 8.10 & 429 & 13.8 & 18.6 & 368 & 11.8 & 16.1 & 0.93 & 0.86 & 0.07 \\
\hline Montenegro & 0.798 & 49 & 16.09 & 407 & 65.6 & 39.2 & 333 & 53.6 & 30.6 & 0.95 & 0.82 & 0.13 \\
\hline Morocco & 0.636 & 111 & 1.21 & 6391 & 17.7 & 17.0 & 6303 & 17.5 & 16.8 & 0.90 & 0.99 & -0.09 \\
\hline Myanmar & 0.541 & 134 & 0.08 & 7524 & 14.0 & 14.8 & 7347 & 13.7 & 14.5 & 0.89 & 0.98 & -0.09 \\
\hline Namibia & 0.612 & 116 & 4.78 & 62 & 2.4 & 4.2 & 61 & 2.4 & 4.1 & 0.95 & 1.00 & -0.05 \\
\hline
\end{tabular}




\begin{tabular}{|c|c|c|c|c|c|c|c|c|c|c|c|c|}
\hline Netherlands & 0.921 & 6 & 12.23 & 11713 & 70.1 & 32.4 & 9652 & 57.8 & 24.9 & 0.89 & 0.82 & 0.07 \\
\hline Nicaragua & 0.625 & 114 & 0.49 & 289 & 4.6 & 5.5 & 269 & 4.3 & 5.1 & 0.90 & 0.93 & -0.03 \\
\hline Niger & 0.338 & 173 & 0.17 & 40 & 0.2 & 0.4 & 40 & 0.2 & 0.4 & 1.00 & 1.00 & 0.00 \\
\hline Oman & 0.804 & 45 & 6.88 & 109 & 2.3 & 4.5 & 106 & 2.2 & 4.4 & 0.92 & 0.96 & -0.04 \\
\hline Pakistan & 0.533 & 136 & 0.33 & 9574 & 4.8 & 6.9 & 9069 & 4.5 & 6.6 & 0.87 & 0.94 & -0.07 \\
\hline Panama & 0.770 & 62 & 9.58 & 378 & 9.2 & 8.2 & 333 & 8.1 & 7.2 & 0.90 & 0.88 & 0.02 \\
\hline $\begin{array}{l}\text { Papua New } \\
\text { Guinea }\end{array}$ & 0.508 & 140 & 0.41 & 603 & 7.2 & 11.6 & 597 & 7.1 & 11.5 & 0.88 & 0.99 & -0.11 \\
\hline Paraguay & 0.697 & 92 & 1.03 & 700 & 10.2 & 11.2 & 667 & 9.7 & 10.7 & 0.89 & 0.95 & -0.06 \\
\hline Philippines & 0.684 & 98 & 1.09 & 16597 & 15.6 & 19.9 & 14803 & 13.9 & 17.9 & 0.86 & 0.89 & -0.03 \\
\hline Poland & 0.836 & 35 & 10.60 & 26968 & 72.3 & 35.7 & 24910 & 66.7 & 32.3 & 0.89 & 0.92 & -0.03 \\
\hline Portugal & 0.829 & 38 & 27.43 & 4766 & 47.8 & 21.9 & 4144 & 41.5 & 18.2 & 0.82 & 0.87 & -0.05 \\
\hline Qatar & 0.850 & 31 & 8.30 & 71 & 2.6 & 7.8 & 66 & 2.4 & 7.5 & 0.90 & 0.92 & -0.02 \\
\hline Romania & 0.796 & 52 & 5.44 & 10862 & 56.6 & 29.3 & 9804 & 51.1 & 25.9 & 0.87 & 0.90 & -0.03 \\
\hline Samoa & 0.696 & 93 & 5.25 & 56 & 28.5 & 34.2 & 27 & 13.7 & 16.3 & 1.00 & 0.48 & 0.52 \\
\hline Saudi Arabia & 0.837 & 34 & 3.82 & 898 & 2.7 & 4.1 & 754 & 2.3 & 3.6 & 0.90 & 0.85 & 0.05 \\
\hline Senegal & 0.489 & 148 & 0.35 & 182 & 1.1 & 2.2 & 170 & 1.0 & 2.1 & 0.89 & 0.91 & -0.02 \\
\hline Serbia & 0.772 & 60 & 13.67 & 7851 & 91.1 & 49.8 & 6619 & 76.8 & 39.4 & 0.89 & 0.84 & 0.05 \\
\hline Sierra Leone & 0.413 & 167 & 0.33 & 84 & 1.1 & 2.3 & 80 & 1.0 & 2.2 & 1.00 & 0.91 & 0.09 \\
\hline Slovenia & 0.876 & 23 & 13.51 & 1390 & 68.5 & 32.1 & 1176 & 58.0 & 26.1 & 0.83 & 0.85 & -0.02 \\
\hline South Africa & 0.673 & 102 & 0.97 & 7867 & 13.7 & 16.4 & 7398 & 12.9 & 15.5 & 0.90 & 0.94 & -0.04 \\
\hline South Korea & 0.890 & 21 & 35.38 & 26285 & 52.1 & 26.0 & 17579 & 34.8 & 16.2 & 0.78 & 0.67 & 0.11 \\
\hline Spain & 0.873 & 25 & 13.85 & 24812 & 55.3 & 26.3 & 19998 & 44.6 & 20.4 & 0.79 & 0.81 & -0.02 \\
\hline Sri Lanka & 0.762 & 67 & 1.69 & 1386 & 6.7 & 5.0 & 1143 & 5.5 & 4.1 & 0.89 & 0.82 & 0.07 \\
\hline Sudan & 0.485 & 150 & 1.13 & 541 & 1.3 & 2.2 & 508 & 1.2 & 2.1 & 0.90 & 0.92 & -0.02 \\
\hline Suriname & 0.720 & 86 & 7.42 & 95 & 16.8 & 15.4 & 91 & 16.1 & 14.8 & 0.91 & 0.96 & -0.05 \\
\hline Tajikistan & 0.639 & 110 & 1.10 & 322 & 3.5 & 5.4 & 304 & 3.3 & 5.1 & 0.91 & 0.94 & -0.03 \\
\hline Tanzania & 0.501 & 145 & 0.12 & 149 & 0.3 & 0.5 & 148 & 0.3 & 0.5 & 1.00 & 1.00 & 0.00 \\
\hline Thailand & 0.733 & 81 & 5.95 & 21492 & 31.4 & 18.9 & 19816 & 29.0 & 17.8 & 0.91 & 0.92 & -0.01 \\
\hline Togo & 0.484 & 151 & 0.73 & 75 & 0.9 & 1.9 & 74 & 0.9 & 1.8 & 0.88 & 0.99 & -0.11 \\
\hline $\begin{array}{l}\text { Trinidad and } \\
\text { Tobago }\end{array}$ & 0.784 & 55 & 2.98 & 239 & 17.5 & 12.4 & 197 & 14.5 & 10.2 & 0.90 & 0.83 & 0.07 \\
\hline Tunisia & 0.721 & 85 & 8.91 & 1851 & 16.0 & 13.6 & 1760 & 15.2 & 13.0 & 0.90 & 0.95 & -0.05 \\
\hline Turkey & 0.765 & 65 & 14.52 & 33235 & 40.8 & 35.6 & 32377 & 39.8 & 34.8 & 0.89 & 0.98 & -0.09 \\
\hline Uganda & 0.497 & 147 & 0.45 & 464 & 1.0 & 2.7 & 439 & 1.0 & 2.7 & 0.91 & 0.99 & -0.08 \\
\hline Uruguay & 0.788 & 53 & 12.91 & 1452 & 42.9 & 27.2 & 1315 & 38.8 & 24.2 & 0.95 & 0.90 & 0.05 \\
\hline Vanuatu & 0.584 & 122 & 0.00 & 14 & 5.0 & 8.0 & 15 & 5.3 & 8.7 & 0.92 & 1.06 & -0.14 \\
\hline Yemen & 0.501 & 146 & 3.61 & 544 & 1.9 & 3.9 & 542 & 1.9 & 3.9 & 0.88 & 1.00 & -0.12 \\
\hline Zambia & 0.552 & 128 & 0.21 & 233 & 1.3 & 3.4 & 228 & 1.3 & 3.4 & 1.00 & 1.00 & 0.00 \\
\hline Zimbabwe & 0.516 & 139 & 0.42 & 310 & 1.8 & 4.0 & 298 & 1.8 & 4.0 & 0.90 & 1.00 & -0.10 \\
\hline
\end{tabular}


(A)

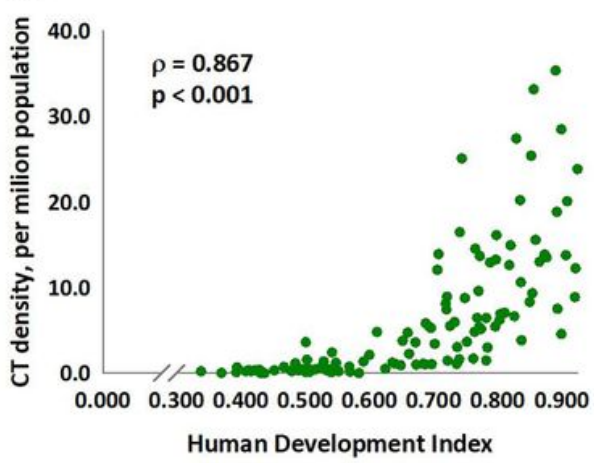

(B)

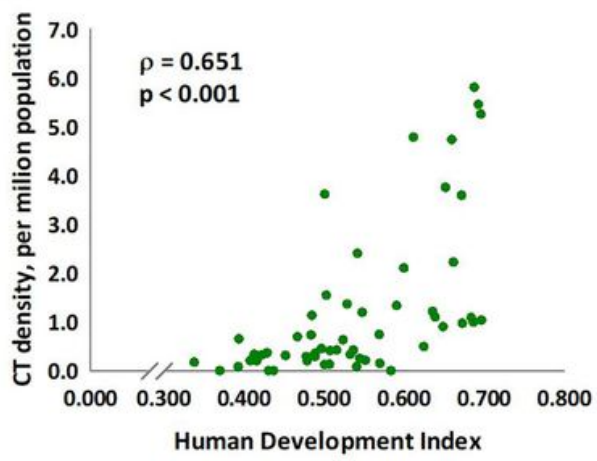

(c)

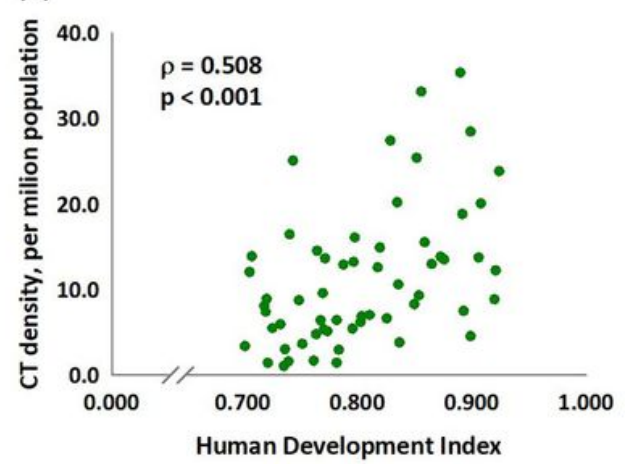

Figure 1

The human development index of (A) all selected countries $(n=115)$, and of countries with (B) HDI score $<0.70$ ( $n=56)$, and $(C)$ HDI score $\geqq 0.70$ ( $n=59)$, are significantly associated with CT density.
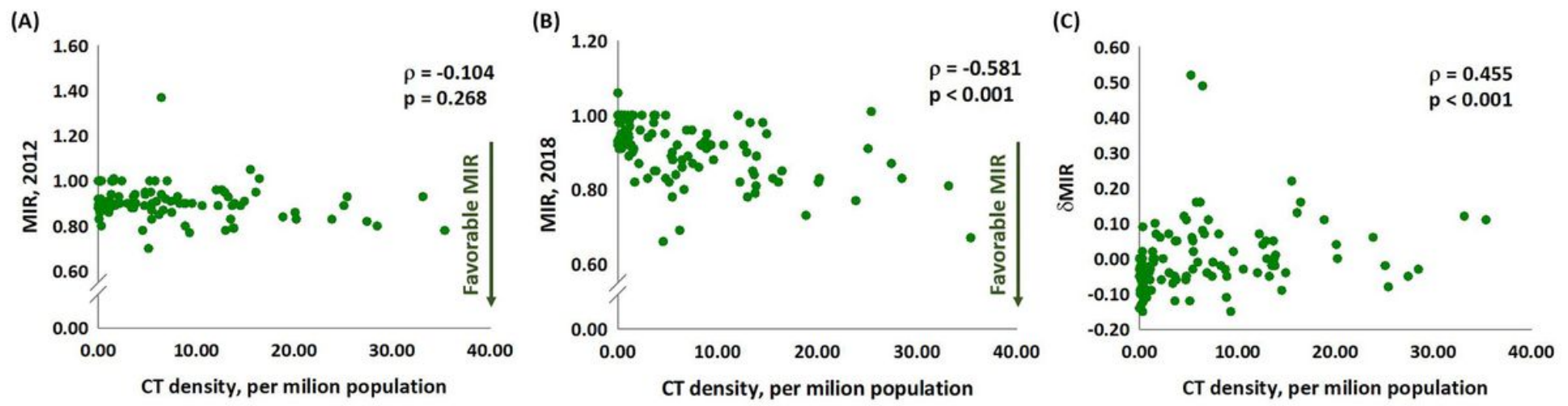

Figure 2

Lack of an association between CT density and MIR in 2012 (A). However, the CT density is significantly associated with (B) MIR in 2018 and (C) 6 MIR in lung cancer. 